\title{
FKBP52 deficiency-conferred uterine progesterone resistance is genetic background and pregnancy stage specific
}

\author{
Susanne Tranguch, ${ }^{1}$ Haibin Wang, ${ }^{1}$ Takiko Daikoku, ${ }^{1}$ Huirong Xie, ${ }^{1}$ \\ David F. Smith, ${ }^{2}$ and Sudhansu K. Dey ${ }^{1}$ \\ 1Department of Pediatrics, Department of Cell and Developmental Biology, Department of Pharmacology, \\ and Division of Reproductive and Developmental Biology, Vanderbilt University Medical Center, Nashville, Tennessee, USA. \\ 2Department of Biochemistry and Molecular Biology, Mayo Clinic, Scottsdale, Arizona, USA.
}

\begin{abstract}
Immunophilin FKBP52 serves as a cochaperone to govern normal progesterone $\left(\mathrm{P}_{4}\right)$ receptor $(\mathrm{PR})$ function. Using $F k b p 52^{-/-}$mice, we show intriguing aspects of uterine $\mathrm{P}_{4} / \mathrm{PR}$ signaling during pregnancy. Implantation failure is the major phenotype found in these null females, which is conserved on both C57BL6/129 and CD1 backgrounds. However, $\mathrm{P}_{4}$ supplementation rescued implantation and subsequent decidualization in $\mathrm{CD} 1$, but not C57BL6/129, null females. Surprisingly, experimentally induced decidualization in the absence of blastocysts failed in $F k b p 52^{-/-}$mice on either background even with $\mathrm{P}_{4}$ supplementation, suggesting that embryonic signals complement uterine signaling for this event. Another interesting finding was that while $\mathrm{P}_{4}$ at higher than normal pregnancy levels conferred PR signaling sufficient for implantation in CD1 null females, these levels were inefficient in maintaining pregnancy to full term. However, elevating $\mathrm{P}_{4}$ levels further restored $\mathrm{PR}$ signaling to a level optimal for successful term pregnancy with normal litter size. Collectively, the results show that the indispensability of FKBP52 in uterine $\mathrm{P}_{4} / \mathrm{PR}$ signaling is a function of genetic disparity and is pregnancy stage specific. Since there is evidence for a correlation between $P_{4}$ supplementation and reduced risks of $P_{4}$-resistant recurrent miscarriages and remission of endometriosis, these findings have clinical implications for genetically diverse populations of women.
\end{abstract}

\section{Introduction}

Progesterone $\left(\mathrm{P}_{4}\right)$ signaling is an absolute requirement for implantation and pregnancy maintenance in all eutherian mammals studied $(1,2) . \mathrm{P}_{4}$ acts through its nuclear $\mathrm{P}_{4}$ receptor $(\mathrm{PR})$ to activate transcription of genes involved in ovulation, uterine receptivity, implantation, decidualization, and pregnancy maintenance. This is evident from the complete infertility of female mice lacking Pgr, the gene encoding PR (3). The failure of ovulation and implantation precludes using $\mathrm{Pgr}^{-/-}$mice to study potential new aspects of $\mathrm{P}_{4}$ function during pregnancy. In contrast, the targeted deletion of the Fkbp52 gene, which encodes FKBP52, an immunophilin cochaperone that optimizes PR signaling, has allowed us to address unique aspects of uterine $\mathrm{P}_{4} / \mathrm{PR}$ signaling during pregnancy in mice.

Immunophilins are so named because of their ability to bind and mediate the actions of certain immunosuppressive drugs. They are grouped into 2 families, FK506-binding proteins (FKBPs) and cyclosporin A-binding proteins (cyclophilins [CyPs]). Some FKBP and CyP family members contain a tetratricopeptide repeat (TPR) domain that targets binding to the highly conserved $C$ terminus of Hsp90. FKBP52, FKBP51, and CyP40 are 3 such TPR-containing cochaperones that have been identified in steroid receptor complexes (4). Like other steroid receptors, PR assembles in an ordered, multistep manner for hormone binding $(5,6)$; the final complex

Nonstandard abbreviations used: Areg, amphiregulin; FKBP, FK506-binding protein; ICI, ICI 182,780; I $h$ h, Indian hedgehog; IS, implantation site; Lif, leukemia inhibitory factor; $L t f$, lactoferrin; $\mathrm{MEF}$, mouse embryonic fibroblast; $\mathrm{P}_{4}$, progesterone; $\mathrm{PR}$, $\mathrm{P}_{4}$ receptor; TPR, tetratricopeptide repeat.

Conflict of interest: The authors have declared that no conflict of interest exists. Citation for this article: J. Clin. Invest. 117:1824-1834 (2007). doi:10.1172/JCI31622. involves direct association of Hsp90 with PR, which stabilizes its ability to bind $\mathrm{P}_{4}(7)$. At the mature stage, FKBPs and other TPR cochaperones dynamically exchange on Hsp90 such that there is a mixture of receptor complexes distinguished by which cochaperone is associated with $\mathrm{Hsp} 90(8,9)$. Hormone binding stimulates interruption of the receptor/chaperone assembly cycle and promotes receptor activation. Recent findings show that cochaperones have unique influences on steroid receptor function. FKBP52 potentiates the responses of $\mathrm{PR}$, androgen receptor, and glucocorticoid receptor to their respective ligands (10-12). In fact, only the mature PR complex bound to FKBP52 is capable of binding $\mathrm{P}_{4}$ with high affinity and efficiency, although basal $P R$ responsiveness to $\mathrm{P}_{4}$ is still retained in the absence of FKBP52. Our recent study (12) revealed the previously unknown role of FKBP52/PR signaling in female reproduction.

The uterus consists of heterogeneous cell types that respond differentially to estrogen and $\mathrm{P}_{4}$. For successful implantation, the uterus must be transiently receptive to implantation-competent blastocysts. For example, the prereceptive uterus on days 1-3 of pregnancy or pseudopregnancy becomes receptive to implantation on day 4 under the direction of $\mathrm{P}_{4}$ and estrogen. By late day 5 , the uterus becomes nonreceptive, since implantation-competent blastocysts transferred into uteri of pseudopregnant mice at this time fail to implant. Following implantation on day 4 evening (2200 to $2400 \mathrm{~h}$ ), uterine stromal cells at the sites of blastocysts undergo extensive proliferation and differentiation, giving rise to decidual cells, a process termed decidualization $(1,13)$. Using proteomic analysis in Hoxa10 $10^{-/}$mouse uteri, we identified FKBP52 as an important signaling molecule in stromal cell function during the periimplantation period (14). Consistent with the role of 

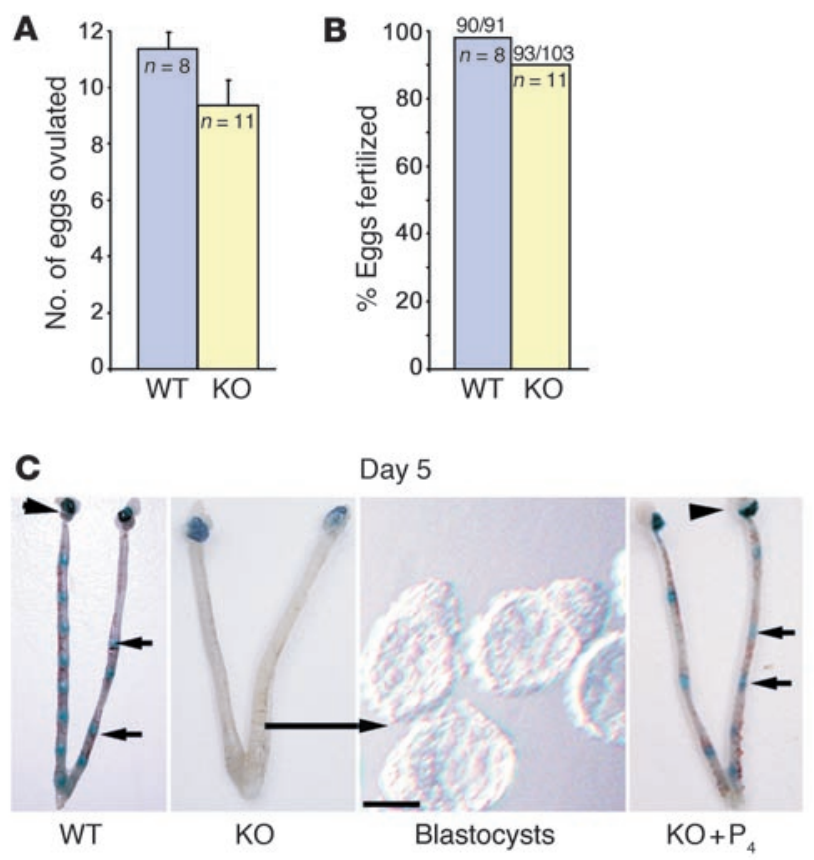

FKBP52 as a PR cochaperone, uterine expression of Fkbp52 and Pgr overlaps on days 4 and 5 of pregnancy (12). More importantly, we have shown that Fkbp52-- females on a C57BL6/129 mixed background have complete implantation failure, with normal ovulation and slightly reduced fertilization rates (12). This phenotype has recently been confirmed by another group in independently

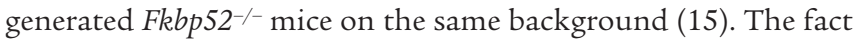
that the infertile phenotype of $F k b 552^{-/-}$females is primarily due to implantation defects suggests differential sensitivity of the ovary and uterus to FKBP52/PR-mediated $\mathrm{P}_{4}$ action. This tissuespecific differential sensitivity is not noted in $\mathrm{Pgr}^{-/-}$females, in which severely compromised ovarian and uterine functions lead to complete female infertility $(3,16)$.

Although $\mathrm{P}_{4}$ is commonly known as the "hormone of pregnancy," various aspects of its roles throughout pregnancy are not well understood. Therefore, $F k b p 52^{-/-}$mice provide a unique opportunity for studying such roles of $\mathrm{P}_{4}$ signaling throughout pregnancy. Using these null mice, we show in the present investigation that $\mathrm{P}_{4} / \mathrm{PR}$ signaling is a function of genetic makeup and is pregnancy stage specific. For example, while the implantation failure phenotype was conserved in both C57BL6/129 and CD1 mice lacking Fkbp52, daily $\mathrm{P}_{4}$ supplementation rescued implantation with subsequent decidualization in CD1 Fkbp52-/- females but not in C57BL6/129 Fkbp52-/- females. Surprisingly, experimentally induced decidualization failed to occur in Fkbp52-/- mice on either background even with exogenous $\mathrm{P}_{4}$ supplementation, suggesting that embryonic signals complement the uterine signaling network. Another interesting finding is the differential requirement for $\mathrm{P}_{4} / \mathrm{PR}$ signaling at specific stages of pregnancy in $\mathrm{P}_{4}$-treated CD1 Fkbp52-/- females. For example, while $\mathrm{P}_{4}$ at higher than normal levels conferred PR signaling sufficient for uterine receptivity and implantation in Fkbp52 $2^{-1-}$ females, these levels did not maintain adequate PR signaling to sustain pregnancy, resulting in reduced litter sizes due to in utero fetal resorption and restricted growth. However, increasing $\mathrm{P}_{4}$ levels even further restored PR signaling, to a degree sufficient to maintain full-term pregnancy with nor-

\section{Figure 1}

$\mathrm{P}_{4}$ supplementation via Silastic implants rescues implantation failure in CD1 Fkbp52--- females. Ovulation (A) and fertilization (B) were examined on day 2 of pregnancy. The number of ovulated eggs was not significantly different in WT and Fkbp52-/- $(\mathrm{KO})$ females. Values are mean \pm SEM; $P>0.05$, unpaired Student's $t$ test. Fertilization rate was determined by counting the number of 2-cell embryos after flushing oviducts. Numbers above the bars indicate the total number of 2 -cell embryos per total number of eggs recovered. The fertilization rate was comparable between WT and KO females $(P>0.05$; unpaired Student's $t$ test). (C) Implantation fails in KO females but is rescued by $\mathrm{P}_{4}$ as examined on day 5 of pregnancy. Implants containing $\mathrm{P}_{4}$ were inserted s.c. in $\mathrm{KO}$ females $\left(\mathrm{KO}+\mathrm{P}_{4}\right)$ on day 2 of pregnancy. Representative photographs of uteri with or without ISs as demarcated by blue bands in $\mathrm{WT}, \mathrm{KO}$, and $\mathrm{KO}+\mathrm{P}_{4}$ mice are shown. Representative photographs of blastocysts recovered from uteri of $\mathrm{KO}$ females without IS. Arrowheads and short arrows indicate the location of ovaries and ISs, respectively. The long arrow indicates the uterus from which unimplanted blastocysts were recovered. Scale bar: $50 \mu \mathrm{m}$.

mal litter size. Collectively, these findings show that FKBP52 deficiency confers uterine $\mathrm{P}_{4}$ resistance during pregnancy, since null females have normal PR and $\mathrm{P}_{4}$ levels with reduced PR activity (12, 17). This study also shows that the requirement for FKBP52 in optimizing PR activity is genetic background dependent and that levels of $\mathrm{P}_{4} / \mathrm{PR}$ signaling required to ensure successful pregnancy differ depending on pregnancy stage.

\section{Results}

Implantation failure occurs in Fkbp52-1- mice irrespective of genetic background. There is increasing evidence that mutation of a gene often results in altered phenotypes depending on the genetic background of mice (18). These varying phenotypes are thought to be due to differential expression and/or regulation of modifier genes (19), although identification of such modifiers remains largely unknown. There is also evidence that compensatory function of genes among the same family is genetic background dependent (20). We have recently shown that C57BL6/129 Fkbp52-/- females have complete implantation failure, although ovulation is normal (12). To determine whether this phenotype is a function of genetic background, we established Fkbp52 deletion in CD1 mice (see Methods). First, we examined ovulation and fertilization in CD1 Fkbp52-/- females after mating them with WT males, since Fkbp52-/- males, irrespective of genetic background, are infertile (10). We found ovulation and fertilization to be comparable to those of WT females (Figure $1, \mathrm{~A}$ and $\mathrm{B}$ ). We then asked whether implantation occurs in these mice. Initiation of implantation accompanies an increased endometrial vascular permeability at sites of blastocysts, which are visualized as distinct blue bands after injection of a blue dye solution $(13,21)$. CD1 Fkbp52-/- females were examined for implantation sites (ISs) by this method on day 5 of pregnancy. We observed that only 2 of 14 CD 1 Fkbp52-/- females showed very faint blue bands (Figure 1C and Table 1). Unimplanted blastocysts were recovered from uterine flushings of null mice with implantation failure (Figure $1 \mathrm{C}$ ), suggesting that although embryos developed to blastocysts, they failed to implant. Our data indicate that optimal $\mathrm{P}_{4} / \mathrm{PR}$ 
Table 1

$\mathrm{P}_{4}$ rescue of implantation failure in CD1 $\mathrm{Fkbp52}^{--}$- female mice

\begin{tabular}{lcccccc} 
Genotype & $\begin{array}{c}\text { Day of } \\
\text { pregnancy }\end{array}$ & $\begin{array}{c}\text { No. of } \\
\text { mice }\end{array}$ & $\begin{array}{c}\text { No. of mice } \\
\text { with IS (\%) }\end{array}$ & $\begin{array}{c}\text { No. of } \\
\text { ISs }\end{array}$ & $\begin{array}{c}\text { Weight } \\
\text { of IS (mg) }\end{array}$ & $\begin{array}{c}\text { No. of embryos } \\
\text { recovered }\end{array}$ \\
WT & 5 & 16 & $16(100 \%)$ & $12.2 \pm 0.3$ & $4.1 \pm 0.3$ & NA \\
& 6 & 9 & $9(100 \%)$ & $13.2 \pm 0.9$ & $10.7 \pm 0.2$ & NA \\
& 8 & 5 & $5(100 \%)$ & $10.8 \pm 1.8$ & $29.3 \pm 1.0$ & NA \\
$\mathrm{K} 0$ & 12 & 11 & $11(100 \%)$ & $13.5 \pm 0.8$ & $214.7 \pm 7.0$ & NA \\
& 5 & 14 & $2(14 \%)$ & $7.0 \pm 0.3$ & NE & $66^{A}$ \\
& 6 & 9 & $4(44 \%)$ & $4.5 \pm 1.2$ & $6.3 \pm 0.1 \mathrm{~B}$ & $21^{\mathrm{C}}$ \\
$\mathrm{K} 0+\mathrm{P}_{4}$ & 8 & 8 & $1(13 \%)$ & 1 & 8.0 & $19^{\mathrm{D}}$ \\
& 12 & 5 & 0 & $\mathrm{NA}$ & $\mathrm{NA}$ & 0 \\
& 5 & 11 & $9(81 \%)$ & $10.3 \pm 0.5$ & $3.75 \pm 0.2$ & $17^{\mathrm{E}}$ \\
& 6 & 6 & $6(100 \%)$ & $10.8 \pm 1.3$ & $7.8 \pm 0.3 \mathrm{~B}$ & $\mathrm{NA}$ \\
& 8 & 8 & $8(100 \%)$ & $11.4 \pm 0.9$ & $19.2 \pm 0.9 \mathrm{~B}$ & $\mathrm{NA}$ \\
& 12 & 14 & $14(100 \%)$ & $11.6 \pm 0.6$ & $127.5 \pm 8.8 \mathrm{~B}$ & $\mathrm{NA}$ \\
\hline
\end{tabular}

WT and CD1 Fkbp52--/ females were mated with WT fertile males, and the number of ISs was determined on days $5,6,8$, and 12 of pregnancy. Fkbp52-/- females were treated with Silastic implants containing $\mathrm{P}_{4}$ $\left(\mathrm{KO}+\mathrm{P}_{4}\right)$ from day 2 of pregnancy until the day of sacrifice. Uteri without ISs were flushed with saline to recover any unimplanted embryos. ASeven mice without ISs yielded 66 blastocysts, of which 6 showed signs of degeneration. ${ }^{\mathrm{B} P}<0.05$ compared with WT, unpaired Student's $t$ test. ${ }^{C}$ Twenty-one blastocysts were recovered from 5 mice, of which 5 showed signs of degeneration. DNineteen blastocysts were recovered from 3 mice, of which 3 had signs of degeneration. ESeventeen blastocysts were recovered from 2 mice. The number and weights of ISs are presented as mean \pm SEM. NE, not examined because ISs were very faint as demarcated by blue reaction, precluding their excision for weighing.

signaling imparted by FKBP52 is critical to uterine receptivity and implantation in mice, a phenotype conserved across these genetic backgrounds. Because ovulation is normal in $F k b p 52^{-/-}$mice, our results suggest that uterine responsiveness to PR signaling differs from ovarian responsiveness. It is possible that relatively high local $\mathrm{P}_{4}$ levels in the ovary (22), the site of its synthesis, enhance basal PR activity sufficient for ovulation and fertilization processes.

$P_{4}$ supplementation rescues implantation in CD1 Fkbp52-- females. We have shown that PR activity, but not PR or $\mathrm{P}_{4}$ levels, is compromised in C57BL6/129 Fkbp52-- females $(12,17)$. It is possible that FKBP52 binding to the PR complex modulates the hormone responsiveness of PR not in an all-or-none fashion, but rather to fine-tune physiological responses to $\mathrm{P}_{4}$. This would imply that while FKBP52 is necessary for optimal PR activity, PR signaling can still operate, albeit not as efficiently, in the absence of FKBP52. Since serum $\mathrm{P}_{4}$ levels in CD1 Fkbp52-- females are similar to those in WT mice on day 5 of pregnancy (Supplemental Figure 1; supplemental material available online with this article; doi:10.1172/JCI31622DS1), we speculated that exposing Fkbp52-/- uteri to higher-than-normal $\mathrm{P}_{4}$ levels would enhance PR activity to rescue pregnancy failure in the absence of FKBP52. This is consistent with our previous findings that PR activity in Fkbp52-/- mouse embryonic fibroblasts (MEFs) reached levels similar to those in WT MEFs exposed to higher $\mathrm{P}_{4}$ concentrations in culture (12). This may also explain why ovulation, a $\mathrm{P}_{4}$-regulated event, is normal in Fkbp52-/- females on both genetic backgrounds.

To determine whether $\mathrm{P}_{4}$ supplementation rescues implantation, we used $\mathrm{P}_{4}$-containing Silastic implants to maintain steady-state hormone levels (23). WT and Fkbp52-/ females were mated with WT males, and Silastic implants containing $\mathrm{P}_{4}$ were placed under the dorsal skin of $F k b p 52^{--}$females from day 2 of pregnancy until the day of sacrifice. We were surprised to see that $\mathrm{P}_{4}$ supplementation not only rescued implantation in CD1 Fkbp52-- females examined on day 5 , but the number of ISs was also comparable to that in WT mice (Figure $1 \mathrm{C}$ and Table 1). In contrast, exogenous $\mathrm{P}_{4}$ supplementation was largely ineffective in rescuing implantation in C57BL6/129 Fkbp52- females; only 3 of $11(27 \%)$ and 2 of $8(25 \%)$ null females showed implantation when examined on days 5 and 8 , respectively. In addition, the number of ISs was also remarkably low, especially on day 8 , compared with that in WT females (Table 2). To circumvent any contribution arising from lower fertilization rates in C57BL6/129 Fkbp52-/ mice, we performed blastocyst transfer experiments. Day-4 WT blastocysts were transferred into uterine lumens of day-4 C57BL6/129 Fkbp52-/- pseudopregnant females carrying Silastic $\mathrm{P}_{4}$ implants from day 2 . Again, we noted extremely poor implantation rates in these mice (Table 3).

$P_{4}$ supplementation restores $P_{4}$ and implantation-regulated gene expression in CD1 Fkbp52-- uteri. $\mathrm{P}_{4}$-regulated events combined with preimplantation estrogen secretion guide the uterus from a prereceptive to receptive state, allowing blastocyst attachment in the uterine wall on day 4 evening. To determine whether rescue of implantation by $\mathrm{P}_{4}$ is reflected in the restoration of $\mathrm{P}_{4}$-dependent uterine gene expression, we placed a Silastic $\mathrm{P}_{4}$ implant on day 2 in CD1 Fkbp52- females that had been mated with WT males and sacrificed them on day 4 of pregnancy. We selected $\mathrm{P}_{4}$-regulated genes that encode Hoxa10, Indian hedgehog (Ihb), and amphiregulin (Areg) because of their participation in uterine receptivity (24-27). In situ hybridization results showed that exogenous $\mathrm{P}_{4}$ treatment considerably restores expression of these genes (Figure 2A).

Lactoferrin (Ltf) and complement factor 3 (C3) are induced to a high degree in the uterus by estrogen and antagonized by $\mathrm{P}_{4}(28$, 29). They are abundantly expressed in the luminal epithelium on
Table 2

$\mathrm{P}_{4}$ fails to rescue implantation failure in C57BL6/129 Fkbp52-- female mice

$\begin{array}{lccccc}\text { Genotype } & \begin{array}{c}\text { Day of } \\ \text { pregnancy }\end{array} & \begin{array}{c}\text { No. of } \\ \text { mice }\end{array} & \begin{array}{c}\text { No. of mice } \\ \text { with IS (\%) }\end{array} & \begin{array}{c}\text { No. of } \\ \text { ISs }\end{array} & \begin{array}{c}\text { No. of embryos } \\ \text { recovered }\end{array} \\ \text { WT } & 5 & 11 & 11(100 \%) & 7.5 \pm 0.5 & \text { NA } \\ \text { KO+P4 } & 5 & 11 & 3(27 \%) & 5.6 \pm 1.0 & 23^{A} \\ \text { KO+P } 4 & 8 & 8 & 2(25 \%) & 2 \pm 0.5^{B} & 0^{C}\end{array}$

WT and Fkbp52-/- females on a C57BL6/129 background were mated with WT fertile males, and the number of ISs was examined on days 5 and 8 of pregnancy by the blue dye method. Fkbp52-/- females were placed with $\mathrm{P}_{4}$ containing Silastic implants from day 2 of pregnancy until the day of sacrifice. Uteri without ISs were flushed with saline to recover any unimplanted embryos. AEight mice without ISs yielded 23 blastocysts, of which 21 showed signs of degeneration. ${ }^{\mathrm{B} P}<0.05$ compared with WT, unpaired Student's $t$ test. 'Six mice without ISs yielded no embryos. The number of ISs is presented as mean \pm SEM. 
Table 3

$\mathrm{P}_{4}$ fails to rescue implantation failure of transferred WT blastocysts in C57BL6/129 Fkbp52-- females

\begin{tabular}{lcccccc}
\multicolumn{2}{c}{$\begin{array}{c}\text { Genotype } \\
\text { Blastocysts }\end{array}$} & $\begin{array}{c}\text { No. of blastocysts } \\
\text { Recipients }\end{array}$ & $\begin{array}{c}\text { No. of } \\
\text { transferred }\end{array}$ & $\begin{array}{c}\text { No. of mice } \\
\text { recipients }\end{array}$ & $\begin{array}{c}\text { No. of } \\
\text { with (\%) (\%) }\end{array}$ & $\begin{array}{c}\text { No. of embryos } \\
\text { recovered }\end{array}$ \\
WT & WT & 82 & 6 & $6(100 \%)$ & $49 / 82(59 \%)$ & NA \\
WT & KO+P & 83 & 5 & $2(40 \%)$ & $6 / 83(7 \%)$ & $45^{A}$
\end{tabular}

Day-4 WT blastocysts were transferred into uteri of WT or KO recipients on day 4 of pseudopregnancy. Fkbp52--females were treated with Silastic implants containing $\mathrm{P}_{4}$ from days 2 through 5 of pseudopregnancy. Recipients were examined for ISs on day 5 by the blue dye method. Uteri without ISs were flushed with saline to recover any unim-



the site of blastocysts in CD1 Fkbp52-1- females with failed implantation in the absence of $\mathrm{P}_{4}, \mathrm{P}_{4}$ supplementation restored implantation with correct expression of these genes (Figure 3, A and B). The ability of $\mathrm{P}_{4}$ to rescue both implantation and Lif expression on day 5 of pregnancy in Fkbp52-/- mice without salvaging Lif expression on day 4 agrees with previous

day 1 of pregnancy under the influence of a preovulatory estrogen surge but are dramatically downregulated on day 4 by rising $\mathrm{P}_{4}$ levels from newly formed corpora lutea $(1,2)$. However, in CD1 Fkbp52-/- mice, uterine expression of these genes was aberrantly elevated on day 4 but downregulated with exogenous $\mathrm{P}_{4}$ supplementation (Figure $2 \mathrm{~B}$ ). Together, these findings provide evidence that $\mathrm{P}_{4}$ supplementation restores the expression of $\mathrm{P}_{4}$-regulated genes and counters the expression of estrogen target genes in CD1 Fkbp52-/- uteri, shifting the uterus to a $\mathrm{P}_{4}$-dominated milieu conducive to uterine receptivity as opposed to one of estrogenic dominance that is detrimental to uterine receptivity.

The fact that exogenous $\mathrm{P}_{4}$ treatment fully rescues implantation in CD1 Fkbp52-/- females but is largely ineffective in C57BL6/129 Fkbp52 $2^{-/}$mice led us to examine whether $\mathrm{P}_{4}$ treatment would restore the expression of $\mathrm{P}_{4}$-regulated genes in C57BL6/129

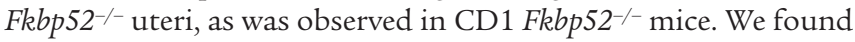
that although exogenous $\mathrm{P}_{4}$ treatment considerably restored Hoxa10 and Ihb expression, Areg expression remained low to undetectable (Supplemental Figure 2A). More interestingly, exogenous $\mathrm{P}_{4}$, which normally inhibits estrogen-responsive Ltf expression in CD1 Fkbp52-/- uteri on day 4, was not effective in attenuating Ltf expression in C57BL6/129 Fkbp52-/- uteri (Supplemental Figure 2B). Overall, these results imply that while C57BL6/129 Fkbp52-/uteri are somewhat responsive to $\mathrm{P}_{4}$ induction of target genes, they are less receptive to $\mathrm{P}_{4}$ 's influence in antagonizing estrogen target genes. These findings are significant, since excess estrogenic influence leads to uterine nonreceptivity (30). Because implantation fails in most C57BL6/129 Fkbp52 $2^{-/-}$mice even after $\mathrm{P}_{4}$ treatment, we performed subsequent experiments on CD1 Fkbp52-/- mice.

Although expression of several $\mathrm{P}_{4}$-regulated genes was considerably restored with $\mathrm{P}_{4}$ supplementation in CD1 Fkbp52-/- uteri, the expression of leukemia inhibitory factor ( $L$ if $)$, normally expressed in day-4 WT pregnant uterine glands, was not restored by $\mathrm{P}_{4}$ treatment in these null mice (Figure $3 \mathrm{~A}$ ). We next determined whether $\mathrm{P}_{4}$ rescue of implantation on day 5 in CD 1 Fkbp52-/- mice is accompanied by correct expression of implantation-related genes, such as Lif, Ptgs2, and Bmp2 (31-33). We found that while these genes were not expressed at

\section{Figure 2}

$\mathrm{P}_{4}$ supplementation via Silastic implants corrects misexpression of genes in CD1 Fkbp52-/- uteri. (A) In situ hybridization of $\mathrm{P}_{4}$-regulated genes Hoxa10, Ihh, and Areg in WT, KO, and $\mathrm{KO}+\mathrm{P}_{4}$ uteri on day 4 of pregnancy. (B) In situ hybridization of estrogen-target genes $L t f$ and complement factor $3(\mathrm{C} 3)$ in $\mathrm{WT}, \mathrm{KO}$, and $\mathrm{KO}+\mathrm{P}_{4}$ uteri on day 4 of pregnancy. Implants containing $\mathrm{P}_{4}$ were inserted s.c. in $\mathrm{KO}$ females on day 2 of pregnancy. ge, glandular epithelium; le, luminal epithelium; myo, myometrium; s, stroma. Scale bar: $200 \mu \mathrm{m}$. observations that the first phase of Lif expression on day 4 is not as critical as its second phase of expression in stromal cells surrounding the implanting blastocyst $(33,34)$.

Upon closer examination of WT and null uterine histology, we came across an interesting observation. A significant decrease in the number of glands was noted in null uteri on both genetic backgrounds (Figure 3C), a phenotype not rescued by $\mathrm{P}_{4}$ supplementation (data not shown). This decrease in gland numbers, however, does not fully account for the altered expression of Areg, Ihh, or Lif in null uteri, since the glands that were still present failed to show
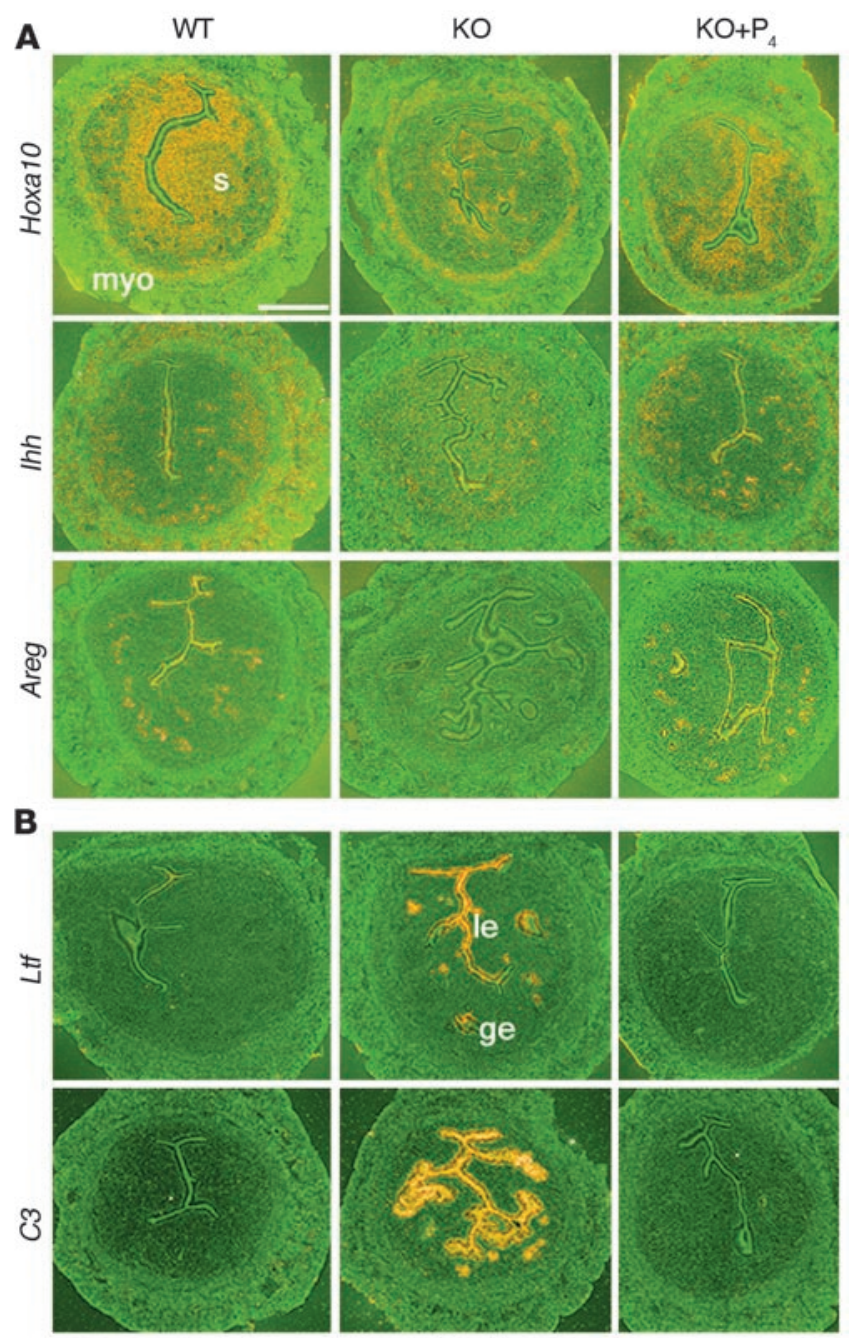

Day 4 
A

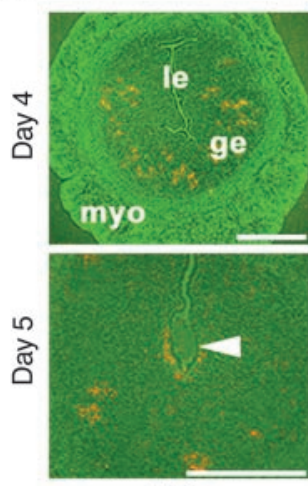

WT

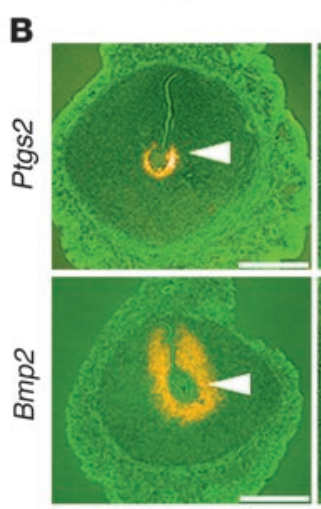

WT
Lif

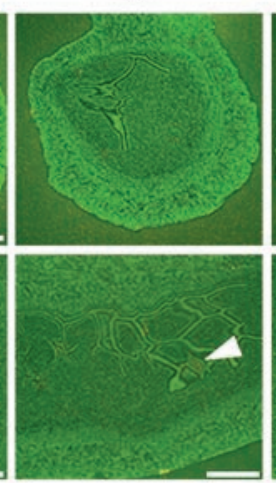

KO

Day 5

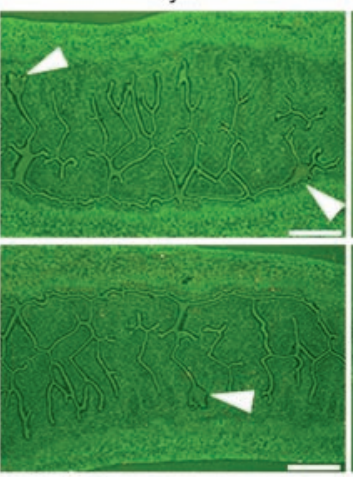

$\mathrm{KO}$

\section{C}

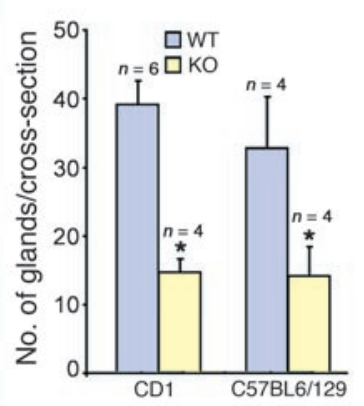

Figure 3

Delivery of $\mathrm{P}_{4}$ via Silastic implants restores expression of implantationrelated genes in CD1 Fkbp52-/- females. (A) In situ hybridization of Lif in WT, KO, and $\mathrm{KO}+\mathrm{P}_{4}$ uteri on days 4 and 5 of pregnancy. (B) In situ hybridization of Ptgs2 and $\mathrm{Bmp} 2$ in $\mathrm{WT}, \mathrm{KO}$, and $\mathrm{KO}+\mathrm{P}_{4}$ uteri on day 5 of pregnancy. $\mathrm{P}_{4}$ implants were inserted s.c. in KO females on day 2 of pregnancy. Arrowheads in A and $\mathbf{B}$ indicate the location of embryos. Scale bars: $200 \mu \mathrm{m}$. (C) Number of glands per uterine cross-section of WT and KO uteri on CD1 and C57BL6/129 backgrounds. For each animal, glands were counted in 9-12 uterine sections. Numbers above bars indicate number of mice evaluated. Values are mean \pm SEM. ${ }^{*} P<0.05$, unpaired Student's $t$ test. normal expression patterns of these genes. There is clear evidence that both estrogen and $\mathrm{P}_{4}$ participate in uterine gland formation in sheep $(35,36)$. Our data also implicate a potential role for FKBP52/ $\mathrm{PR}$ signaling in mouse uterine gland formation and function. This is an exciting finding but warrants further investigation.

Postimplantation defects in $P_{4}$-treated CD1 Fkbp52-/- females. Our observation of unimplanted blastocysts recovered from CD1 Fkbp52-1- females examined on day 5 of pregnancy suggested deferral of implantation timing in these mice as is observed in $c P L A 2 a^{-/-}$ or $L P A 3^{-/-}$mice $(37,38)$. To test for this possibility, we sacrificed CD1 Fkbp52-1- mice on days 6 and 8 of pregnancy. We found that unlike in $\mathrm{CPLA} 2 \mathrm{a}^{-/-}$or $\mathrm{LPA3}^{-/-}$mice, implantation timing was not altered; rather implantation drastically failed in Fkbp52-- females (Figure 4, A and B, and Table 1). Again, blastocysts were recovered from CD1 Fkbp52-/- uteri on these days, confirming implantation as the major defect in these mice (Figure 4, A and B, and Table 1).

We next determined whether $\mathrm{P}_{4}$ supplementation could sustain pregnancy beyond day 5 . To our surprise, we found that placing Silastic $\mathrm{P}_{4}$ implants in null females allowed progression of pregnancy in $100 \%$ of CD 1 Fkbp52-/- females examined on days 6, 8, and 12 of pregnancy (Figure 4, A-C, and Table 1). However, ISs in $\mathrm{P}_{4}$-treated CD1 Fkbp52than those in WT uteri (Table 1), suggesting a somewhat compromised decidual response.

Experimentally induced decidualization fails in Fkbp52-/- mice irrespective of $\mathrm{P}_{4}$ treatment. In pseudopregnant mice in the absence of embryos, the steroid hormonal milieu and responsiveness of the uterus on days 1 through 4 are similar to those of normal pregnancy. Various artificial stimuli, including intraluminal infusion of oil, can initiate many aspects of the decidual cell reaction in pseudopregnant mice if applied on day 4. Decidualization, characterized by stromal cell proliferation and differentiation into specialized types of cells with polyploidy, is critical to pregnancy establishment in many species (1). In fact, decidualization does not occur in $\mathrm{Pgr}^{-/-}$mice $(3,16)$, demonstrating an absolute requirement for $\mathrm{P}_{4} / \mathrm{PR}$ signaling in this process.

We asked whether experimentally induced decidualization occurs in Fkbp52-/- females on both genetic backgrounds using the model of intraluminal oil infusion and if not, whether $\mathrm{P}_{4}$ supplementation could rescue this phenotype. We observed severely compromised decidualization in both C57BL6/129 and CD1 Fkbp52-females when compared with WT littermates (Figure 4, D and E). Interestingly, $\mathrm{P}_{4}$ treatment could not restore decidualization in Fkbp52-/- mice on either strain, with only a few swellings noted along the oil-infused uterine horn (Figure 4, D and E). That $\mathrm{P}_{4}$ treatment rescues blastocyst implantation with decidualization in CD1 Fkbp52-/- females but not experimentally induced decidualization is remarkable. This agrees with previous observations that gene expression differs in the decidual bed induced by blastocysts from that induced experimentally (39). Differences in decidualization in these 2 models (oil-induced versus blastocyst-induced) were noted even at the ultrastructural level (40).

$P_{4}$ delivery via Silastic implants partially restores full-term pregnancy in CD1 Fkbp52-/- females. To investigate whether $\mathrm{P}_{4}$ supplementation maintains full-term pregnancy in CD1 Fkbp52- females, $\mathrm{P}_{4}$ implants placed on day 2 were removed on day 17 , since $\mathrm{P}_{4}$ withdrawal is necessary to initiate labor (41). Although 9 of 13 Fkbp52-/mothers delivered pups of normal weight, litter sizes were sig- 

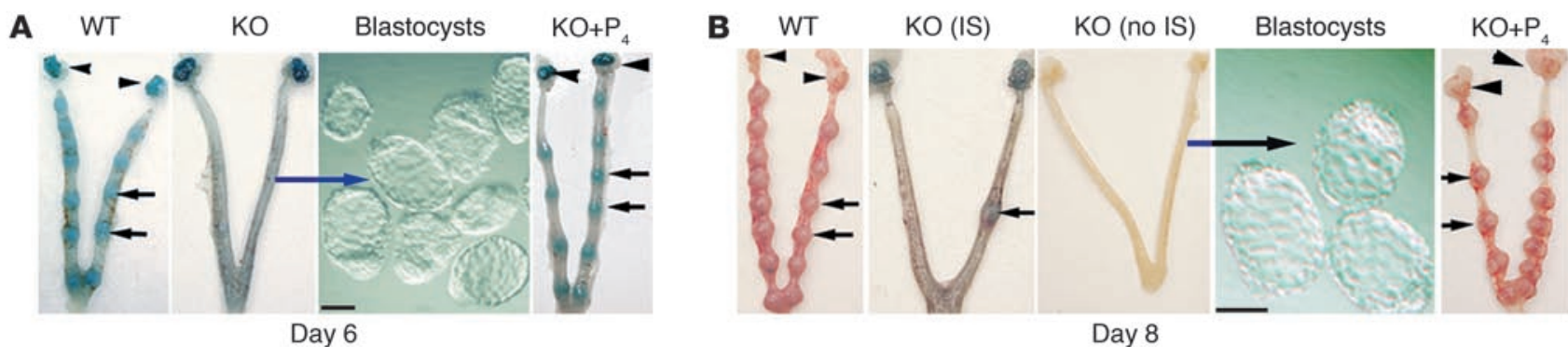

Day 8

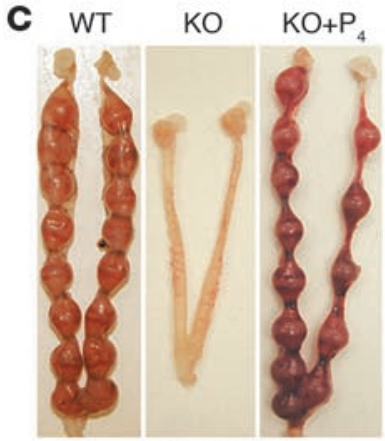

Day 12

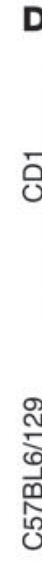

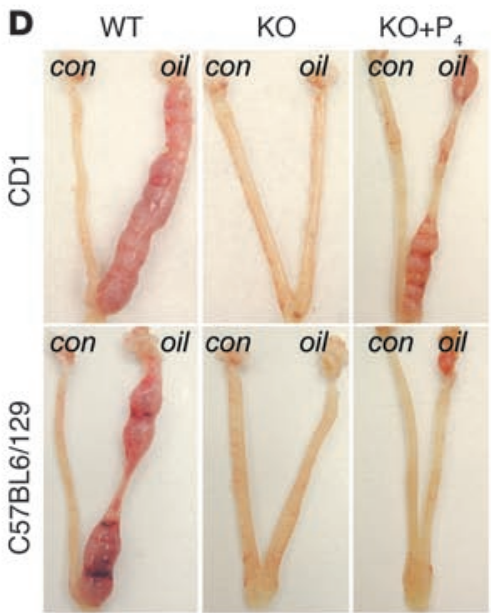

$\mathbf{E}$

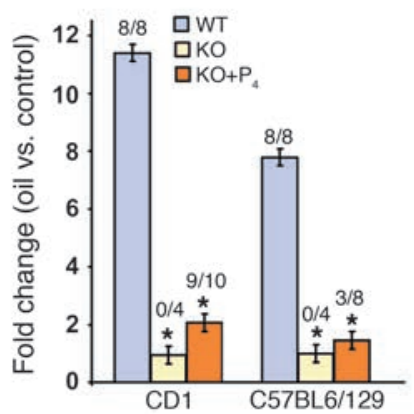

Figure 4

Deciduoma (day 8)

$\mathrm{P}_{4}$ delivery via Silastic implants rescues blastocyst-induced, but not oil-induced, decidualization in Fkbp52-/- females. Representative photographs of WT, KO, and $\mathrm{KO}+\mathrm{P}_{4}$ uteri on day $6(\mathbf{A})$, day $8(\mathbf{B})$, and day $12(\mathbf{C})$ of pregnancy are shown. Arrowheads and short arrows indicate the location of ovary and IS, respectively. Representative images of recovered unimplanted blastocysts from uteri (long arrow) of KO females without ISs are shown. Scale bars: $50 \mu \mathrm{m}$. (D) Oil-induced decidualization fails in KO females on both CD1 and C57BL6/129 backgrounds. Representative photomicrographs of WT, KO, and KO+P 4 uteri on day 8 of pseudopregnancy. On day 4 of pseudopregnancy, $25 \mu \mathrm{l}$ of oil was infused intraluminally in one uterine horn (oil); the contralateral horn without oil infusion served as a control (con). (E) Fold changes in weight between oil-infused and noninfused (control) uterine horns. Numbers above the bars indicate the number of mice with decidual response per total number of mice examined. Fold changes are presented as mean $\pm \mathrm{SEM}$; ${ }^{*} P<0.05$, unpaired Student's $t$ test.

nificantly smaller (Figure 5A). This led us to determine when embryonic loss occurs in null females carrying $\mathrm{P}_{4}$ implants. We observed that 70 of 106 ISs were resorbing in $\mathrm{P}_{4}$ implant-treated Fkbp52-/- uteri when examined on day 14, compared with only 9 of 194 in WT uteri (Figure 5, B and C). Resorbing ISs in $\mathrm{P}_{4}$-treated Fkbp52-/- females appeared dark blue and were infiltrated with a massive number of blood cells (Figure 5B). In addition, cytokeratin staining of sections of ISs with normal appearance from null females carrying $\mathrm{P}_{4}$ implants showed placentas with less-developed and ill-defined spongiotrophoblast and labyrinth layers compared with those of WT females (Figure 5D).

Although $\mathrm{P}_{4} / \mathrm{PR}$ signaling is absolutely required for pregnancy maintenance in all eutherians thus far studied, uterine FKBP52 expression in later days of pregnancy has not yet been examined. We found that while FKBP52 is expressed in the mesometrial decidua with high expression in the placenta on days 10-14 of pregnancy, PR is mostly expressed in the decidua (Supplemental Figure 3, A and B, and data not shown). Embryonic signals direct normal decidual functions and development (39), which in turn govern placentation and embryonic growth (42). Therefore, the expression of FKBP52 and PR in the decidua suggests that maternally derived FKBP52-mediated PR signaling contributes to feto- placental well-being, while placental expression of FKBP52 suggests a PR-independent role for FKBP52.

Excessive estrogenic influence or complement activation does not contribute to pregnancy failure in $\mathrm{P}_{4}$-implanted $F k b p 52^{-1-}$ females. We speculated that one possible explanation for the higher incidence of resorptions in Fkbp52-/- females carrying $\mathrm{P}_{4}$ implants is the tipping of the balance between estrogen and $\mathrm{P}_{4}$ signaling toward estrogenic dominance. Since high levels of estrogen are detrimental to pregnancy success (30), we examined whether combined treatment with $\mathrm{P}_{4}$ implants and ICI 182,780 (ICI; $25 \mu \mathrm{g}$ or $125 \mu \mathrm{g} / 0.1 \mathrm{ml}$ oil/mouse, s.c.), an estrogen receptor antagonist (Tocris Bioscience), injected on days 8-13 improves pregnancy maintenance. Combined treatment with $\mathrm{P}_{4}$ and the high dose of ICI increased the resorption rate to $100 \%$ in $F k b p 52^{-1-}$ mice, while treatment with a lower dose of ICI resulted in resorption rates similar to those observed in null mice receiving $\mathrm{P}_{4}$ implants alone (Supplemental Figure 4). Our observation that treatment with a higher dose of ICI results in increased resorption rates suggests that appropriate estrogen signaling is also critical to pregnancy maintenance. This agrees with a previous study showing that pregnancy maintenance under the direction of $\mathrm{P}_{4}$ is supported by low amounts of estrogen, especially on days 10 and 11 of pregnancy (43). 

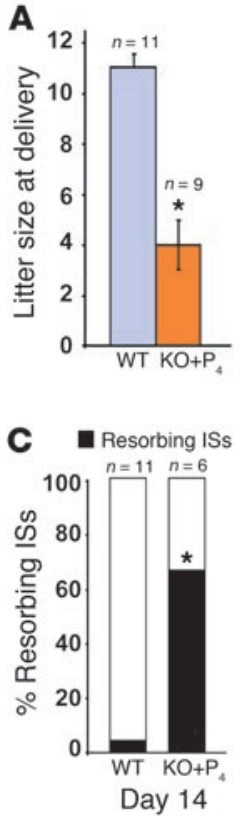

B

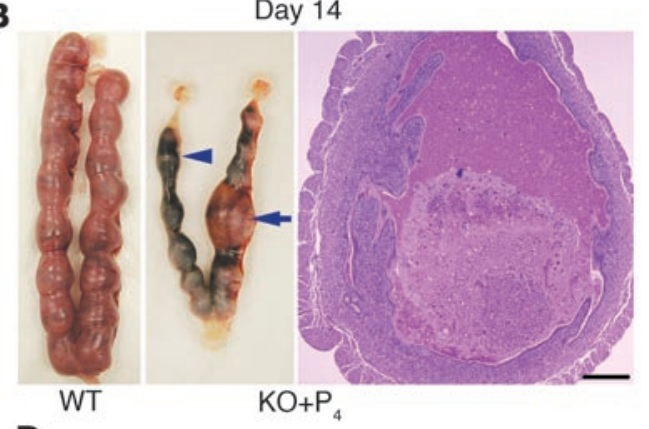

D

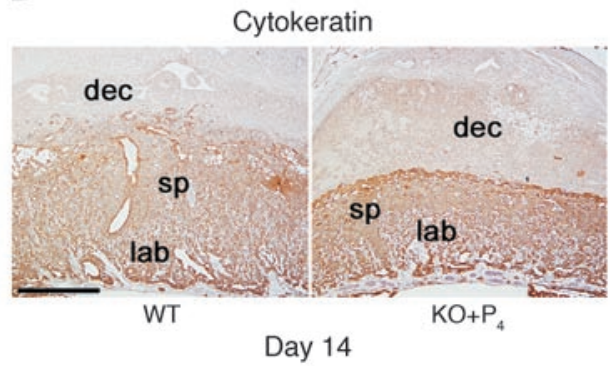

While the underlying causes of recurrent pregnancy failure are not well understood, one possibility is that the maternal immune response mistakenly recognizes the fetus. A recent study shows that complement activation causes growth restriction and subsequent fetal rejection, leading to pregnancy failure (44). We speculated that this pathway is activated due to reduced PR signaling from FKBP52 deficiency, especially since $\mathrm{P}_{4}$ has antiinflammatory roles within and outside the uterus $(17,45)$. Since low doses of heparin inhibit the complement pathway $(44,46), F k b p 52^{-/-}$mice carrying $\mathrm{P}_{4}$ implants from day 2 were given a low dose of heparin (10 U/mouse) twice a day on days 8,10 , and 12 of pregnancy. However, this treatment also failed to rescue pregnancy maintenance in these mice (Supplemental Figure 4), suggesting that activation of the complement pathway is not a major contributing factor for pregnancy failure in $\mathrm{P}_{4}$-treated Fkbp52-/- mice.

Differential $P_{4} / P R$ signaling is required for successful full-term pregnancy. Normal serum $\mathrm{P}_{4}$ levels during pregnancy in CD1 WT mice on days 5 and 14 of pregnancy range between 40 and $47 \mathrm{ng} / \mathrm{ml}$ (Supplemental Figure 1 and Figure 6A). In our experiments, Silastic $\mathrm{P}_{4}$ implants provided an increase in serum $\mathrm{P}_{4}$ levels sufficient to induce uterine receptivity and rescue implantation in CD1 Fkbp52-/- females but failed to maintain pregnancy to full term. We speculated that further increasing $\mathrm{P}_{4}$ levels would rectify this failure. We injected $\mathrm{P}_{4}$ s.c. at a dose of $2 \mathrm{mg} / \mathrm{ml}$ per mouse daily to further increase $\mathrm{P}_{4}$ serum levels. We observed that in null mice, serum $\mathrm{P}_{4}$ levels increased to approximately $156 \mathrm{ng} / \mathrm{ml}$ by daily injection as compared with approximately $100 \mathrm{ng} / \mathrm{ml}$ in mice treated with $\mathrm{P}_{4}$ implants, as assessed on day 14 of pregnancy (Figure 6A). To our surprise, these elevated $\mathrm{P}_{4}$ levels significantly improved pregnancy maintenance in null females; the number and weights of ISs on day 14 were comparable to those in WT mothers (Figure 6, B-D). Pregnancy maintenance in WT mice exposed to a similar $\mathrm{P}_{4}$ injection regimen was normal (data not shown).

Our next objective was to examine whether daily $\mathrm{P}_{4}$ injection results in pregnancy to full term in null females. CD1 Fkbp52-/females mated with WT males were injected with $\mathrm{P}_{4}$ daily from days 2 through 17 of pregnancy and monitored for term delivery

\section{Figure 5}

$\mathrm{P}_{4}$ delivery by Silastic implants fails to sustain pregnancy to full term. (A) Average litter size of WT and $\mathrm{KO}+\mathrm{P}_{4}$ mothers. Litter size is presented as mean $\pm \mathrm{SEM}$; ${ }^{*} P<0.05$, unpaired Student's $t$ test. (B) Representative photomicrographs of WT and $\mathrm{KO}+\mathrm{P}_{4}$ uteri on day 14 of pregnancy. Arrowheads and arrows indicate resorbing and normal IS, respectively. A representative H\&Estained section of resorbing IS from $\mathrm{KO}+\mathrm{P}_{4}$ uterus shows massive infiltration of blood cells. Scale bar: $200 \mu \mathrm{m}$. (C) Percentage of resorption sites in WT and $\mathrm{KO}+\mathrm{P}_{4}$ mice on day 14 of pregnancy. ${ }^{*} P<0.05$, unpaired Student's $t$ test. (D) Cytokeratin staining of WT and $\mathrm{KO}+\mathrm{P}_{4}$ IS on day 14. Scale bar: $200 \mu \mathrm{m}$. dec, decidua; lab, labyrinth; sp, spongiotrophoblast.

on day 20. We observed that all $\mathrm{P}_{4}$-injected null females carried pups to term, and the average litter size was comparable to that of WT mothers (Figure 6E). Pup weights from null and WT mothers at weaning and during early development were also similar (data not shown).

\section{Discussion}

Although $\mathrm{P}_{4}$ signaling via $\mathrm{PR}$ is critical to ovulation, fertilization, implantation, postimplantation growth, and pregnancy maintenance, it is not known whether a similar $\mathrm{P}_{4} / \mathrm{PR}$ signaling mechanism determines these target and stage-specific functions or whether genetic disparity influences this signaling. By using Fkbp52-/- females with compromised PR signaling as opposed to $\mathrm{Pgr}^{-/-}$females with total infertility $(3,12)$, we address these issues for the first time to our knowledge. Our previous and present investigations provide clear evidence that the major reproductive phenotype in mice lacking Fkbp52 is unique to uterine deficiency in the context of implantation. The reason for the organ-specific dependence on FKBP52 for appropriate PR signaling is not clearly understood, but it is noteworthy, since ovulation that also requires $\mathrm{P}_{4} / \mathrm{PR}$ signaling is normal in null females. It is possible that relatively higher $\mathrm{P}_{4}$ levels locally in the ovary override the reduced $\mathrm{PR}$ signaling in the absence of FKBP52. We were also surprised to note that $\mathrm{P}_{4} / \mathrm{PR}$-regulated mating behavior appears normal, since null females mate and produce copulatory plugs. One possibility is that the uterus requires more robust $\mathrm{P}_{4} / \mathrm{PR}$ signaling during pregnancy than other $\mathrm{P}_{4}$ targets. Alternatively, FKBP52, in addition to its role in influencing PR signaling, may have a unique PR-independent role in the uterus not observed in other tissues.

$\mathrm{P}_{4}$ signaling via $\mathrm{PR}$ plays major roles at essentially all stages of pregnancy, from ovulation through parturition. It is surprising to see that genetic makeup of a species alters such a fundamental signaling pathway. While FKBP52 is essential to support implantation in both strains of mice in the absence of exogenous P $_{4}$, FKBP52's role becomes less significant in CD1 mice exposed to high levels of $\mathrm{P}_{4}$, while still remaining crucial in C57BL6/129 mice under similar treatment conditions. The contrasting reproductive phenotypes of Fkbp52-/- mice on C57BL6/129 and CD1 backgrounds with respect to $\mathrm{P}_{4}$ rescue provides the first evidence to our knowledge that $\mathrm{P}_{4} / \mathrm{PR} / \mathrm{FKBP} 52$ signaling is a function of genetic makeup. Coordinated interactions of $\mathrm{P}_{4}$ and estrogen are essential to uterine receptivity and implantation. While one aspect of $\mathrm{P}_{4}$ signaling is to correctly orchestrate $\mathrm{P}_{4}$-responsive genes, another is to appropriately constrain and/or synergize estrogen-responsive genes in the uterus. One cause of implantation failure in C57BL6/129, but not in CD1, Fkbp52-1- females supplemented with $\mathrm{P}_{4}$ could be the failure of the 


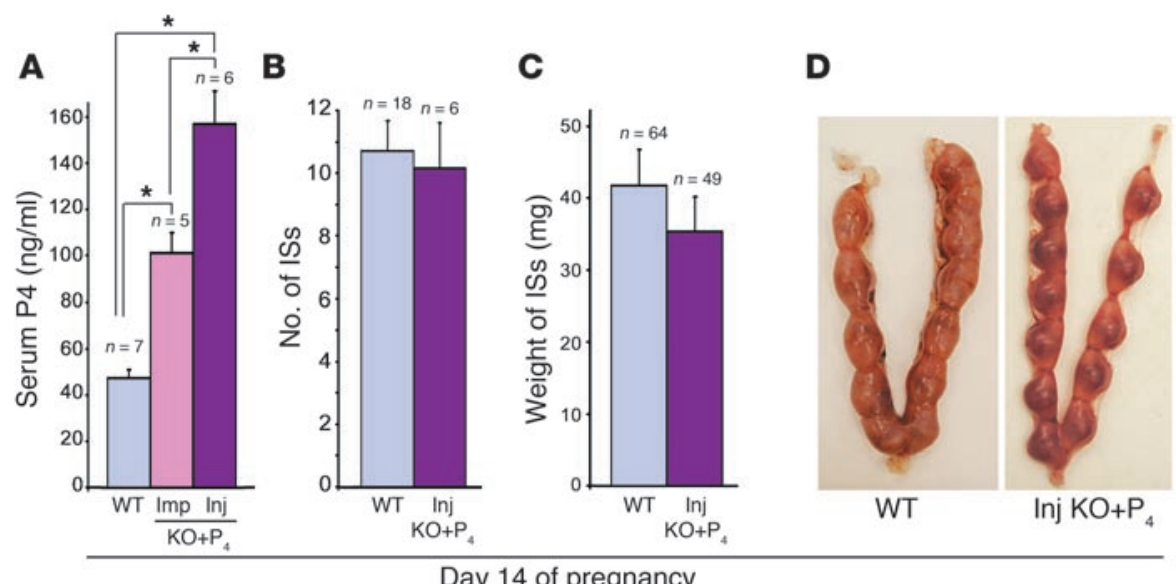

E

\section{Figure 6}

Day 14 of pregnancy

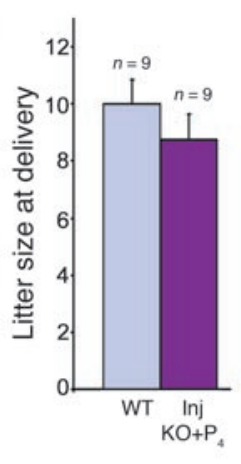

Daily $\mathrm{P}_{4}$ injections restore pregnancy to full term in CD1 Fkbp52-/- females. (A) Serum $\mathrm{P}_{4}$ levels in WT and KO+P 4 mice on day 14 of pregnancy.

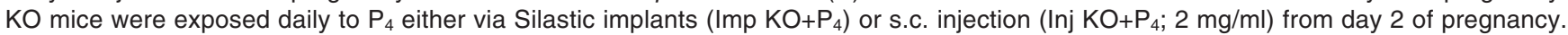
${ }^{*} P<0.05$, univariate ANOVA. (B) The average number of ISs was not significantly different in WT and Inj KO+ $\mathrm{P}_{4}$ mice on day $14 ; P>0.1$, unpaired Student's $t$ test. (C) Weights of ISs from WT and Inj KO+ $\mathrm{P}_{4}$ mice on day 14 of pregnancy were not significantly different; $P>0.1$, unpaired Student's $t$ test. (D) A representative photomicrograph of WT and Inj KO+P 4 uteri on day 14 of pregnancy is shown. (E) The average litter size of WT and Inj KO+P 4 mice was not significantly different; $P>0.05$, unpaired Student's $t$ test. All values are mean \pm SEM.

uterus to attain optimal receptivity arising from altered expression of Areg and/or Ltf. This inappropriate gene expression in the presence of $\mathrm{P}_{4}$ may reflect even lower basal PR activity in C57BL6/129

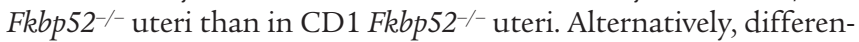
tial expression of modifier genes in these 2 strains of mice could contribute to differential uterine responsiveness to $\mathrm{P}_{4} / \mathrm{PR}$ signaling in the absence of FKBP52.

There is evidence that rodent blastocysts synthesize $\mathrm{P}_{4}$ or structurally similar steroids (47-49) and that gene expression differs in embryo-induced decidua and experimentally induced deciduoma (39). Since our previous results show that Fkbp52 and Pgr are expressed in blastocysts (12), it is possible that $\mathrm{P}_{4}$ synthesized from blastocysts enhances PR/FKBP52 signaling locally at their sites of apposition in the uterus. This could explain the failure of oil-induced decidualization but not of that induced by implanting blastocysts in CD1 Fkbp52 $2^{-/-}$mice supplemented with $\mathrm{P}_{4}$. Alternatively, signaling arising from blastocysts may influence other uterine functions. For example, the gene encoding heparin-binding epidermal growth factor-like growth factor (HB-EGF) is expressed in implantation-competent blastocysts, which can induce uterine Hbegf to initiate the implantation cascade. In fact, Affi-Gel Blue beads (Bio-Rad) presoaked in HB-EGF, when transferred into uterine lumens of pseudopregnant mice on day 4, show implantation-like responses similar to those induced by living blastocysts, including upregulation of Hbegf and $B m p 2(32,50)$.

$\mathrm{P}_{4} / \mathrm{PR}$ signaling is critical throughout pregnancy until its downregulation for the onset of parturition. Indeed, ovariectomizing mice at practically any stage of pregnancy causes resorptions and/or abortion (51). However, the magnitude of this signaling during various stages of pregnancy remains unknown. Although $\mathrm{P}_{4}$ implants cannot rescue pregnancy in WT mice ovariectomized on day 8 unless they are given daily $\mathrm{P}_{4}$ injections, similar $\mathrm{P}_{4}$ injections alone maintain full-term pregnancy in mice ovariectomized on day 14 (51). The use of Fkbp52-/- females has enabled us to show that the requirement for $\mathrm{P}_{4} / \mathrm{PR}$ signaling is different for uterine receptivity, implantation, and postimplantation growth.
This signaling appears to be tightly regulated, since blood levels of approximately $100 \mathrm{ng} / \mathrm{ml}$ of $\mathrm{P}_{4}$ are adequate to induce uterine receptivity and implantation, but levels above $150 \mathrm{ng} / \mathrm{ml}$ are required for full complement of pregnancy success in the absence of FKBP52. This suggests that more robust $\mathrm{P}_{4} / \mathrm{PR}$ signaling is required for pregnancy maintenance than is required for uterine receptivity, implantation, and decidualization. It is also possible that a burst of $\mathrm{P}_{4}$ levels as provided by daily injections is more amenable to pregnancy sustenance than the relatively constant levels maintained with Silastic implants.

The observation that differential $\mathrm{P}_{4}$ levels are required for various stages of pregnancy implies that signaling targets are different. We believe that $\mathrm{P}_{4} / \mathrm{PR}$ signaling for uterine preparation, implantation, and decidualization is primarily targeted to uterine epithelial and stromal cells. This is consistent with $\mathrm{P}_{4}$ 's known roles in epithelial differentiation and stromal cell proliferation during the periimplantation period. On the other hand, $\mathrm{P}_{4} / \mathrm{PR}$ signaling for pregnancy maintenance is directed more toward keeping the myometrium quiescent until parturition and providing sanctuary for the growing fetus from mother's immunological surveillance. $\mathrm{P}_{4} / \mathrm{PR}$ signaling is also known to regulate angiogenesis (52), a process integral to placental development and pregnancy maintenance. Since the events during the course of pregnancy are very dynamic, $\mathrm{P}_{4} / \mathrm{PR}$ signaling at various targets could be overlapping. We consider FKBP52's influence on $\mathrm{P}_{4} / \mathrm{PR}$ signaling during pregnancy to be primarily of maternal origin, since both PR and FKBP52 are expressed in the decidua on days 10 and 12 of pregnancy. The high expression of FKBP52 in the placenta implies a PR-independent role for FKBP52 in placentation. This requires further investigation, but the putative PR-independent role is not critical, since pregnancies are completed to term with normal litter sizes in CD1 Fkbp52-null females receiving daily $\mathrm{P}_{4}$ injections.

An interesting observation is the successful nursing of pups to weaning by $\mathrm{P}_{4}$-injected CD 1 Fkbp52-/- mothers. Mammary morphogenesis during pregnancy requires $\mathrm{P}_{4} / \mathrm{PR}$ signaling $(16,53)$, but the latter stages of lactogenesis and lactation correspond to withdrawal 
of this signaling (reviewed in ref. 54). It was recently reported that FKBP52 may not be critical for $\mathrm{P}_{4} / \mathrm{PR}$ signaling in the mammary gland, since exogenously provided $\mathrm{P}_{4}$ could stimulate mammary morphogenesis in Fkbp52-/- mice (15). This is similar to the findings of our studies in which Fkbp52-/- mothers were injected with exogenous $\mathrm{P}_{4}$ prior to parturition. These results suggest that exogenously supplemented $\mathrm{P}_{4}$ overcomes the $\mathrm{P}_{4}$-resistant state in the mammary gland and uterus in the absence of FKBP52.

The implanting blastocyst is the stimulus for normal decidualization in mice. However, in humans, stromal cells undergo decidualization during the receptive phase in each menstrual cycle in the absence of blastocysts. This predecidualization is thought to be critical for blastocyst implantation in the pregnant uterus (55). Our findings that $\mathrm{P}_{4}$ supplementation fails to rescue oil-induced decidualization in Fkbp52-null uteri may therefore have implication for predecidualization events in $\mathrm{P}_{4}$-resistant women.

$\mathrm{P}_{4}$ resistance is also a hallmark of endometriosis, a condition that affects an estimated 5 million women of childbearing age in the United States (National Women's Health Information Center, National Institute of Child Health and Human Development [NICHD], NIH) (56-58). In fact, a recent study examining global gene expression profiles in endometria of women with or without endometriosis found dysregulation of many known $\mathrm{P}_{4}$ target genes during the window of uterine receptivity (59). While the mechanism(s) of $\mathrm{P}_{4}$ resistance remain unclear, one speculation is that downregulation of $\mathrm{PR}$ contributes to $\mathrm{P}_{4}$ resistance; however, other studies refute this concept (57). Whether FKBP52 expression differs in normal and endometriotic tissues has not been examined.

The finding that human FKBP52 interacts with and potentiates human PR activity in MEFs (12) and our preliminary observation on a limited number of samples showing FKBP52 and PR expression in human endometria in proliferative and secretory phases (data not shown) suggest a potential role for uterine $\mathrm{P}_{4} / \mathrm{PR} / \mathrm{FKBP} 52$ signaling in women. In fact, 3 separate clinical trials found that $\mathrm{P}_{4}$ treatment resulted in a statistically significant decrease in miscarriages in women with a history of 3 or more consecutive pregnancy losses (60). In this respect, pregnancy rescue in CD1 Fkbp52-- mice by daily $\mathrm{P}_{4}$ injections is clinically relevant for women who are infertile due to $\mathrm{P}_{4}$ resistance. These are exciting results, especially since no significant differences in adverse effects were found between $\mathrm{P}_{4}$ treatment and control groups. These findings in humans are similar to our findings in mice that exogenous $\mathrm{P}_{4}$ injections in WT females do not adversely affect pregnancy (data not shown). Fkbp52-1- mice with normal $\mathrm{PR}$ and $\mathrm{P}_{4}$ levels but reduced $\mathrm{PR}$ activity constitute a unique model for studying $\mathrm{P}_{4}$ resistance specifically in uterine biology, and it is hoped that our findings will encourage the development of human studies to determine whether FKBP52 status influences $\mathrm{P}_{4}$ resistance in the uterus.

\section{Methods}

Mice. The Fkbp52 gene was disrupted in mice by homologous recombination, as previously described (10). Tail genomic DNA was used for PCRbased genotyping. Because genetic backgrounds of mice contribute to different phenotypes $(18,20)$, we introduced Fkbp 52 deficiency in CD1 mice by crossing C57BL6/129 Fkbp52 heterozygous males to CD1 WT females producing an $\mathrm{F}_{1}$ generation. $\mathrm{F}_{1}$ Fkbp52 $2^{+-}$males were then back-crossed to $\mathrm{CD} 1$ WT females, and the process was continued for 10 generations. Crossing heterozygous females with heterozygous males of the same genetic background $\left(\mathrm{CD} 1 / \mathrm{F}_{10}\right)$ generated Fkbp52-null and WT littermates for experiments. Mice on both backgrounds were housed and used in the present investigation in accordance with $\mathrm{NIH}$, and animal protocol was approved by the Vanderbilt Institutional Animal Care and Use Committee.

Ovulation, fertilization, implantation, blastocyst transfer, and experimentally induced decidualization. Mice were examined for ovulation, fertilization, and implantation as described previously (37). To examine ovulation and fertilization, CD1 WT or Fkbp52-/- mice were mated with fertile WT males. On day 2 of pregnancy (the day the vaginal plug was first observed was considered day 1), oviducts were flushed with Whitten's medium to recover ovulated eggs, and fertilization was assessed by the number of 2 -cell embryos. ISs on days 5 and 6 of pregnancy were visualized by an i.v. injection $(0.1 \mathrm{ml} / \mathrm{mouse}$ ) of Chicago blue B dye solution ( $1 \%$ in saline), and the number of ISs demarcated by distinct blue bands was recorded. For blastocyst transfer, pseudopregnant recipients were generated by mating females with vasectomized WT males. Day-4 WT blastocysts were transferred into day-4 uteri of C57BL6/129 WT or Fkbp52-/- pseudopregnant recipients, and ISs were examined 24 hours (day 5) or 96 hours (day 8) later by the blue dye method (32).

To determine whether experimentally induced decidualization occurs in null females, WT or Fkbp52-/- females were mated with vasectomized WT males. On day 4, one uterine horn was infused with sesame oil (25 $\mu$ l), while the contralateral horn served as control. Mice were sacrificed on day 8 of pseudopregnancy. Weights of infused (oil) and noninfused (control) uterine horns were recorded, and fold increase in weight was used as an index of decidualization. All mice used were between 2 and 5 months of age.

Exogenous $\mathrm{P}_{4}$ supplementation and other treatments. To see whether $\mathrm{P}_{4}$ supplementation rescues the infertility phenotype of $F k b p 52^{--}$females, null females were mated with WT males, and a Silastic implant $(4 \mathrm{~cm}$ length $\times 0.31 \mathrm{~cm}$ diameter) containing $\mathrm{P}_{4}$ was placed under the dorsal skin on day 2 of pregnancy. Implants were removed upon sacrifice on days 5,6 , and 8 to examine implantation; days 12 or 14 to examine pregnancy maintenance; or day 17 to allow labor to complete full-term pregnancy. Alternatively, null female mice were given a daily injection of $\mathrm{P}_{4}(2 \mathrm{mg} / 0.1 \mathrm{ml} / \mathrm{mouse}$, s.c.) from days 2 through 14 to monitor pregnancy maintenance or through day 17 to allow labor to ensue on day 20 for full-term pregnancy.

To determine the contribution of the complement pathway to pregnancy maintenance, Silastic $\mathrm{P}_{4}$ implants were placed under the dorsal skin on day 2 of pregnancy, and heparin ( $10 \mathrm{U} / 0.1 \mathrm{ml} /$ mouse in saline) was injected s.c. twice a day on days 8,10 , and 12 of pregnancy. To determine whether the $\mathrm{P}_{4}$ /estrogen ratio influences pregnancy maintenance, Silastic $\mathrm{P}_{4}$ implants were placed under the dorsal skin on day 2 of pregnancy, and ICI $(25 \mu \mathrm{g}$ or $125 \mu \mathrm{g} / 0.1 \mathrm{ml} / \mathrm{mouse}$ in sesame oil), an estrogen receptor antagonist, was injected once a day on days 8 through 13 of pregnancy.

To determine whether $\mathrm{P}_{4}$ supplementation rescues experimentally induced decidualization in null females, WT or Fkbp52-/- females were mated with vasectomized WT males, and $\mathrm{P}_{4}$ was either injected daily from day 2 or Silastic $\mathrm{P}_{4}$ implants placed under the dorsal skin on day 2 of pseudopregnancy. On day 4, while the uterine lumen of one horn was infused with sesame oil $(25 \mu \mathrm{l})$, the noninfused contralateral horn served as a control. Mice were sacrificed on day 8 of pseudopregnancy. Uterine weights of oil-infused and noninfused horns were recorded, and fold increases in weight were recorded as an index of decidualization.

$P_{4}$ assay. Blood samples from mice were collected on the indicated days of pregnancy. Serum was separated by centrifugation ( $850 \mathrm{~g}$ for $15 \mathrm{~min}$ utes) and stored at $-80^{\circ} \mathrm{C}$ until analysis. Serum $\mathrm{P}_{4}$ levels were measured by radioimmunoassay.

In situ hybridization. Sense or antisense ${ }^{35} \mathrm{~S}$-labeled cRNA probes for Areg, Ihh, Hoxa10, Ltf, C3, Lif, Bmp2, Ptgs2, Pgr, and Fkbp52 generated using appropriate polymerases from respective cDNAs were used for hybridization as described previously by us (61). Sections hybridized with sense probes showed no positive signals and served as negative controls. 
Immunohistochemistry. Immunolocalization of cytokeratin was performed using a polyclonal rabbit anti-cow antibody (Dako). A Histostain-Plus (DAB) kit (Zymed) was used to visualize antigen. Brown deposits indicated sites of positive immunostaining.

Statistics. Statistical significance was determined as $P<0.05$ by 1 -tailed Student's $t$ test. To compare serum $\mathrm{P}_{4}$ levels in WT versus $\mathrm{KO}+\mathrm{P}_{4}$ mice on day 14 of pregnancy, statistical significance was determined as $P<0.05$ by univariate ANOVA. All values are presented as mean $\pm \mathrm{SEM}$.

\section{Acknowledgments}

We thank Fuhua $\mathrm{Xu}$ for help with statistical analysis. $\mathrm{P}_{4}$ assays were performed by the University of Virginia Center for Ligand Assay and Analysis Core supported by an NICHD grant (U54 HD28934). This work was supported in part by grants from the
NICHD (HD12304 and HD033994 to S.K. Dey; HD050315 to H. Wang) and NIDDK (DK48218 to D.F. Smith). S. Tranguch was supported by a National Research Service Award fellowship from the National Institute on Drug Abuse (F31 DA021062) and an NIDDK training grant (T32 DK07563).

Received for publication January 25, 2007, and accepted in revised form April 17, 2007.

Address correspondence to: Sudhansu K. Dey, Department of Pediatrics, Division of Reproductive and Developmental Biology, Vanderbilt University Medical Center, MCN-D4100, Nashville, Tennessee 37232-2678, USA. Phone: (615) 322-8642; Fax: (615) 322-4704; E-mail: sk.dey@vanderbilt.edu.
1. Dey, S.K., et al. 2004. Molecular cues to implantation. Endocr. Rev. 25:341-373.

2. Wang, H., and Dey, S.K. 2006. Roadmap to embryo implantation: clues from mouse models. Nat. Rev. Genet. 7:185-199.

3. Lydon, J.P., et al. 1995. Mice lacking progesterone receptor exhibit pleiotropic reproductive abnormalities. Genes Dev. 9:2266-2278.

4. Smith, D.F. 2004. Tetratricopeptide repeat cochaperones in steroid receptor complexes. Cell Stress Chaperones. 9:109-121.

5. Pratt, W.B., and Toft, D.O. 1997. Steroid receptor interactions with heat shock protein and immunophilin chaperones. Endocr. Rev. 18:306-360.

6. Smith, D.F. 2000. Chaperones in progesterone receptor complexes. Semin. Cell Dev. Biol. 11:45-52.

7. Smith, D.F. 1993. Dynamics of heat shock protein 90-progesterone receptor binding and the disactivation loop model for steroid receptor complexes. Mol. Endocrinol. 7:1418-1429.

8. Barent, R.L., et al. 1998. Analysis of FKBP51/ FKBP52 chimeras and mutants for Hsp90 binding and association with progesterone receptor complexes. Mol. Endocrinol. 12:342-354.

9. Riggs, D.L., et al. 2004. Functional specificity of cochaperone interactions with $\mathrm{Hsp} 90$ client proteins. Crit. Rev. Biochem. Mol. Biol. 39:279-295.

10. Cheung-Flynn, J., et al. 2005. Physiological role for the cochaperone FKBP52 in androgen receptor signaling. Mol. Endocrinol. 19:1654-1666.

11. Riggs, D.L., et al. 2003. The Hsp90-binding peptidylprolyl isomerase FKBP52 potentiates glucocorticoid signaling in vivo. EMBO J. 22:1158-1167.

12. Tranguch, S., et al. 2005. Cochaperone immunophilin FKBP52 is critical to uterine receptivity for embryo implantation. Proc. Natl. Acad. Sci. U. S. A. 102:14326-14331.

13. Paria, B.C., Huet-Hudson, Y.M., and Dey, S.K. 1993. Blastocyst's state of activity determines the "window" of implantation in the receptive mouse uterus. Proc. Natl. Acad. Sci. U. S. A. 90:10159-10162.

14. Daikoku, T., et al. 2005. Proteomic analysis identifies immunophilin FK506 binding protein 4 (FKBP52) as a downstream target of Hoxa10 in the periimplantation mouse uterus. Mol. Endocrinol. 19:683-697.

15. Yang, Z., et al. 2006. FK506-binding protein 52 is essential to uterine reproductive physiology controlled by the progesterone receptor A isoform. Mol. Endocrinol. 20:2682-2694.

16. Mulac-Jericevic, B., Mullinax, R.A., DeMayo, F.J., Lydon, J.P., and Conneely, O.M. 2000. Subgroup of reproductive functions of progesterone mediated by progesterone receptor-B isoform. Science. 289:1751-1754.

17. Tranguch, S., Smith, D.F., and Dey, S.K. 2006. Progesterone receptor requires a co-chaperone for signalling in uterine biology and implantation. Reprod. Biomed. Online. 13:651-660.

18. Threadgill, D.W., et al. 1995. Targeted disruption of mouse EGF receptor: effect of genetic background on mutant phenotype. Science. 269:230-234.

19. Bonyadi, M., et al. 1997. Mapping of a major genetic modifier of embryonic lethality in TGF beta 1 knockout mice. Nat. Genet. 15:207-211.

20. Wang, H., et al. 2004. Rescue of female infertility from the loss of cyclooxygenase- 2 by compensatory up-regulation of cyclooxygenase- 1 is a function of genetic makeup. J. Biol. Chem. 279:10649-10658.

21. Psychoyos, A. 1973. Hormonal control of ovoimplantation. Vitam. Horm. 31:201-256.

22. Pointis, G., Rao, B., Latreille, M.T., Mignot, T.M., and Cedard, L. 1981. Progesterone levels in the circulating blood of the ovarian and uterine veins during gestation in the mouse. Biol. Reprod. 24:801-805.

23. Milligan, S.R., and Cohen, P.E. 1994. Silastic implants for delivering physiological concentrations of progesterone to mice. Reprod. Fertil. Dev. 6:235-239.

24. Das, S.K., Chakraborty, I., Paria, B.C., Wang, X.N., Plowman, G., and Dey, S.K. 1995. Amphiregulin is an implantation-specific and progesterone-regulated gene in the mouse uterus. Mol. Endocrinol. 9:691-705.

25. Lim, H., Ma, L., Ma, W.G., Maas, R.L., and Dey, S.K. 1999. Hoxa-10 regulates uterine stromal cell responsiveness to progesterone during implantation and decidualization in the mouse. Mol. Endocrinol. 13:1005-1017.

26. Matsumoto, H., Zhao, X., Das, S.K., Hogan, B.L., and Dey, S.K. 2002. Indian hedgehog as a progesterone-responsive factor mediating epithelialmesenchymal interactions in the mouse uterus. Dev. Biol. 245:280-290.

27. Lee, K., et al. 2006. Indian hedgehog is a major mediator of progesterone signaling in the mouse uterus. Nat. Genet. 38:1204-1209.

28. Heikaus, S., Winterhager, E., Traub, O., and Grummer, R. 2002. Responsiveness of endometrial genes Connexin26, Connexin43, C3 and clusterin to primary estrogen, selective estrogen receptor modulators, phyto- and xenoestrogens. J. Mol. Endocrinol. 29:239-249.

29. McMaster, M.T., Teng, C.T., Dey, S.K., and Andrews, G.K. 1992. Lactoferrin in the mouse uterus: analyses of the preimplantation period and regulation by ovarian steroids. Mol. Endocrinol. 6:101-111.

30. Ma, W.G., Song, H., Das, S.K., Paria, B.C., and Dey, S.K. 2003. Estrogen is a critical determinant that specifies the duration of the window of uterine receptivity for implantation. Proc. Natl. Acad. Sci. U. S. A. 100:2963-2968.

31. Lim, H., et al. 1997. Multiple female reproductive failures in cyclooxygenase 2-deficient mice. Cell. 91:197-208.

32. Paria, B.C., et al. 2001. Cellular and molecular responses of the uterus to embryo implantation can be elicited by locally applied growth factors. Proc. Natl. Acad. Sci. U. S. A. 98:1047-1052.
33. Song, H., Lim, H., Das, S.K., Paria, B.C., and Dey, S.K. 2000. Dysregulation of EGF family of growth factors and COX-2 in the uterus during the preattachment and attachment reactions of the blastocyst with the luminal epithelium correlates with implantation failure in LIF-deficient mice. Mol. Endocrinol. 14:1147-1161.

34. Song, H., and Lim, H. 2006. Evidence for heterodimeric association of leukemia inhibitory factor (LIF) receptor and gp130 in the mouse uterus for LIF signaling during blastocyst implantation. Reproduction. 131:341-349.

35. Carpenter, K.D., Gray, C.A., Bryan, T.M., Welsh, T.H., Jr., and Spencer, T.E. 2003. Estrogen and antiestrogen effects on neonatal ovine uterine development. Biol. Reprod. 69:708-717.

36. Gray, C.A., Bazer, F.W., and Spencer, T.E. 2001. Effects of neonatal progestin exposure on female reproductive tract structure and function in the adult ewe. Biol. Reprod. 64:797-804.

37. Song, H., et al. 2002. Cytosolic phospholipase A2alpha is crucial [correction of A2alpha deficiency is crucial] for 'on-time' embryo implantation that directs subsequent development. Development. 129:2879-2889.

38. Ye, X., et al. 2005. LPA3-mediated lysophosphatidic acid signalling in embryo implantation and spacing. Nature. 435:104-108.

39. Bany, B.M., and Cross, J.C. 2006. Post-implantation mouse conceptuses produce paracrine signals that regulate the uterine endometrium undergoing decidualization. Dev. Biol. 294:445-456.

40. Lundkvist, O., and Nilsson, B.O. 1982. Endometrial ultrastructure in the early uterine response to blastocysts and artificial deciduogenic stimuli in rats. Cell Tissue Res. 225:355-364.

41. McCormack, J.T., and Greenwald, G.S. 1974. Progesterone and oestradiol-17beta concentrations in the peripheral plasma during pregnancy in the mouse. J. Endocrinol. 62:101-107.

42. Bilinski, P., Roopenian, D., and Gossler, A. 1998. Maternal IL-11Ralpha function is required for normal decidua and fetoplacental development in mice. Genes Dev. 12:2234-2243.

43. Milligan, S.R., and Finn, C.A. 1997. Minimal progesterone support required for the maintenance of pregnancy in mice. Hum. Reprod. 12:602-607.

44. Girardi, G., Yarilin, D., Thurman, J.M., Holers, V.M., and Salmon, J.E. 2006. Complement activation induces dysregulation of angiogenic factors and causes fetal rejection and growth restriction. J. Exp. Med. 203:2165-2175.

45. Hardy, D.B., Janowski, B.A., Corey, D.R., and Mendelson, C.R. 2006. Progesterone receptor plays a major antiinflammatory role in human myometrial cells by antagonism of nuclear factor-B activation of cyclooxygenase 2 expression. Mol. Endocrinol. 20:2724-2733.

46. Girardi, G., Redecha, P., and Salmon, J.E. 2004. 
Heparin prevents antiphospholipid antibodyinduced fetal loss by inhibiting complement activation. Nat. Med. 10:1222-1226.

47. Wu, J.T. 1987. Metabolism of progesterone by preimplantation mouse blastocysts in culture. Biol. Reprod. 36:549-556.

48. Wu, J.T., and Liu, Z.H. 1990. Conversion of pregnenolone to progesterone by mouse morulae and blastocysts. J. Reprod. Fertil. 88:93-98.

49. Carson, D.D., Hsu, Y.C., and Lennarz, W.J. 1982. Synthesis of steroids in postimplantation mouse embryos cultured in vitro. Dev. Biol. 91:402-412.

50. Hamatani, T., et al. 2004. Global gene expression analysis identifies molecular pathways distinguishing blastocyst dormancy and activation. Proc. Natl. Acad. Sci. U. S. A. 101:10326-10331.

51. Sharma, R., and Bulmer, D. 1983. The effects of ovariectomy and subsequent progesterone replacement on the uterus of the pregnant mouse. J. Anat. 137:695-703.
52. Ma, W., et al. 2001. Adult tissue angiogenesis: evidence for negative regulation by estrogen in the uterus. Mol. Endocrinol. 15:1983-1992.

53. Mulac-Jericevic, B., Lydon, J.P., DeMayo, F.J., and Conneely, O.M. 2003. Defective mammary gland morphogenesis in mice lacking the progesterone receptor B isoform. Proc. Natl. Acad. Sci. U. S. A 100:9744-9749.

54. Neville, M.C., McFadden, T.B., and Forsyth, I. 2002. Hormonal regulation of mammary differentiation and milk secretion. J. Mammary Gland Biol. Neoplasia. 7:49-66.

55. Chobotova, K., et al. 2005. Heparin-binding epidermal growth factor and its receptors mediate decidualization and potentiate survival of human endometrial stromal cells. J. Clin. Endocrinol. Metab. 90:913-919.

56. Berkley, K.J., Rapkin, A.J., and Papka, R.E. 2005. The pains of endometriosis. Science. 308:1587-1589.

57. Bulun, S.E., et al. 2006. Progesterone resistance in endometriosis: link to failure to metabolize estradiol. Mol. Cell. Endocrinol. 248:94-103.

58. Fang, Z., et al. 2004. Intact progesterone receptors are essential to counteract the proliferative effect of estradiol in a genetically engineered mouse model of endometriosis. Fertil. Steril. 82:673-678.

59. Kao, L.C., et al. 2003. Expression profiling of endometrium from women with endometriosis reveals candidate genes for disease-based implantation failure and infertility. Endocrinology. 144:2870-2881.

60. Oates-Whitehead, R.M., Haas, D.M., and Carrier, J.A. 2003. Progestogen for preventing miscarriage. Cochrane Database Syst. Rev. 2003:CD003511. doi: 10.1002/14651858.CD003511.

61. Das, S.K., et al. 1994. Heparin-binding EGF-like growth factor gene is induced in the mouse uterus temporally by the blastocyst solely at the site of its apposition: a possible ligand for interaction with blastocyst EGF-receptor in implantation. Development. 120:1071-1083. 